The submitied manuxcript has beers authored by a contractor of the U.S. Government under contract No. W-31-1U9-ENG-38 Accordingly, the U. S. Government etains nonexclusive, royalty-free license to publish or reproduce the oulitithed torm of this contribution, or allow oiher 3 to do so, for U. S. Gowermest purposes.
CONF $-850507--42$

DE85 013886

\title{
ANGULAR-DISTRIBUTION NEUTRON-EMISSION SPECTRA OF NIOBIOM FOLLOWING BOMBARDMENT BY FAST NEUTRONS
}

P. T. GUENTHER and A. B. SMITH

Argonne National Laboratory, Argonne, Illinols U.S.A.

\begin{abstract}
Neutron-emission spectra at ten angles between 20 and 160 degrees and incldent neutron energies of $5.9,7.1$ and $8.4 \mathrm{MeV}$ were measured relative to the neutrou fleld emitted after spontaneous fission of $252 \mathrm{cF}$. The angular distribution of inelastically scattered neutrons appears to be essentially isotropic where it can be separated from the dominant elastic scattering peak. Above an excitation energy of $4 \mathrm{MeV}$ the spectra are well described by a Maxwellian tenperature distribution.
\end{abstract}

\section{INTRODUCTION}

The inelastic scattering of fast neutrons is a difficult quantitative problem, both from the experimental and theoretical point of view. Yet the rieed for a reliable description of these processes persists (1). The present paper presents a method of measuring Inelastically scattered neutrons that is both conceptuall.: and experimentally relatively stralghtforward. The central idr.d is to determine by the time-of-flight (TOF) method emission-nc:tron spectra relative to that arising from the spontaneous fission of $252 \mathrm{Cf}$. The latter is reasonably-well defined in the emittedneutron-energy range of 1-8 MeV (2). Preliminary results obtained with this approach are discussed herein for the $\mathrm{Nb}$ continuum. A recent evaluation of nuclear cross sectlons for this nucleus indicates a need for more inelastic-neutron-scattering data ( 3 ).

\section{EXPERLMENTAL PROCEDURES}

The present measurements were made with the ten-channel ToF neutron spectrometer at the ANL/FNG facility (4). The $D(d, n) \mathrm{He}^{3}$ reaction and a gas target assembly were employed as the neutron source, with mean incident-deuteron energy definition of $\pm 20 \mathrm{keV}$ and neutron energy resolutions of 300-500 keV. Emission-neutron spectra were recorded over the angular range of $20-160^{\circ}$ at 5.9 , 

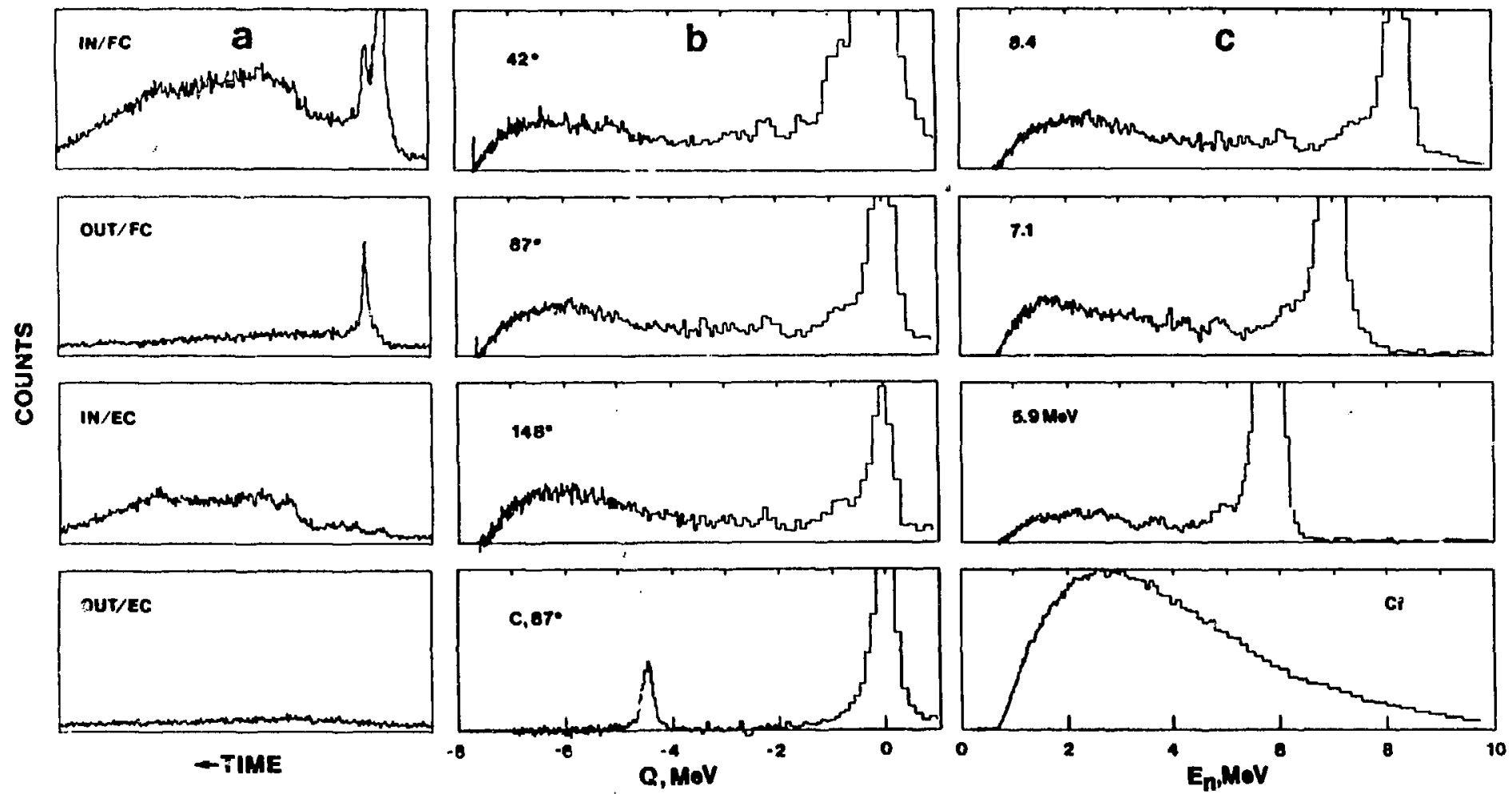

Fig. 1. Neutron Emission Spectra. The sample is $\mathrm{Nb}$ unless noted otherwise. a. Basic time spectra at $8.4 \mathrm{MeV}$ incident-neutron energy $\left(E_{1 n}\right)$. IN (OUT) refers to the sample position in (out) of the beam line. EC (FC) Indicates that the target celi was empty (filled) with deuterium. Reduced spectra follow from the subtractions (IN/FC-OUT/FC)-(IN/EC)-OUT/EC). b. Reduced spectra for selected scattering angles at $E_{1 n}=8.4 \mathrm{MeV}$. c. Reduced spectra at 87 deg. for $E_{1 n}=5.9,7.1,8.4$ $\mathrm{MeV}$. The Cf reference spectrum corresponds to the same detector. 
7.1 and $8.4 \mathrm{MeV}$ inctdent-neutron energies, thus mintmizing complications due to the $D(d ; n, p) D$ source reaction and the $93 \mathrm{Nb}(\mathrm{n}, 2 \mathrm{n}){ }^{92} \mathrm{Nb}$ reaction. The emitted neutrons were detected from $\leq 1 \mathrm{MeV}$ upwards with an energy scale uncertainty of $\leqslant 50 \mathrm{keV}$. Fig. 1 characterizes the time spectra obtained in this work. Scattering from carbon accompanied all measurements in order to monitor the "purity" of the spectra. Also shown in this figure Is the detector response to the Cf neutron-emission spectrum. In the "off-line" method described in ref. 5, the entire spectrometer is used except that the stop pulse is derived from the detection of the Cf fission fragments. Many of the usual corrections are obviated by the present ratio apprcach, and for excitation energies above $2 \mathrm{MeV}$ multiple-scattering requires an essentially isotropic reduction of observed count rates by $<10 z$.

\section{RESULTS ARD CONCLUSIONS}

An Inspection of FIg - 1 suggests several conclusions regarding the inelastic scattering of fast neutrons from $\mathrm{Nb}$. Except for the elastic component, the spectra are essentially isotropic implying a preponderance of compound nuclear process. The

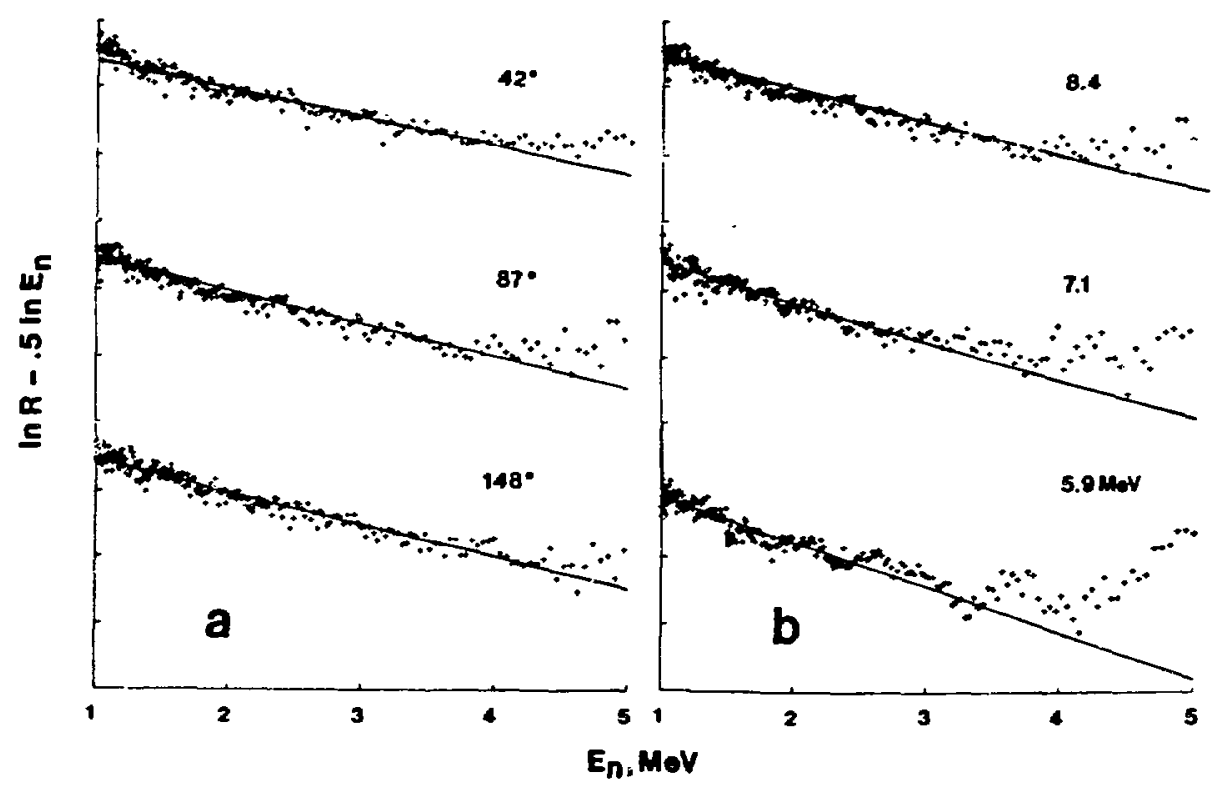

Fig. 2. Experimentally determined Nb/Cf spectrum ratios, R, plotted as $\operatorname{lnR}-0.5 \ln E_{n}$ vs. $E_{n}$. 
P. T. GUENTHER and A. B. SMITH

spectra suggest a transition to the continuum representation above an excitation energy of about $4 \mathrm{MeV}$. In the higher emission energy region there is evidence of experimentally unre-

solved discrete states. The elastic scattering peak tends to dominate much of this part of the spectrum forward of $40^{\circ}$. The continuum portions of the spectra have been analyzed in terms Maxwellian emission distributions. The Cf spectrum has ieen shown to be well described in the present energy range by the form $E^{I / 2} \exp (-E / T)(2)$, while the form $E \exp (-E / T)$ is assumed for $\mathrm{Nb}(6)$. The natural logarithms of the experimentally determined $\mathrm{Nb}-t o-C f-s p e c t r u m$ ratios were least-squares fitted for eacn angle and incident energy to the expression $(a+0.5 \ln E-b E)$, where the slope $b$ may be Identifled with $\left(1 / T_{\mathrm{Nb}}-1 / \mathrm{T}_{\mathrm{Cf}}\right)$. As Fig. 2a demonstrates, $b$ is reasonably constant over that part of the angular range which is experimentally well-defined. The energy variation of $b$ is exhibited in Fig. 2b. The nuclear temperatures implied by these fits were evaluated using the $C f$ temperature suggested by Poenitz and Tamura (2). The results of averaging the individual values are indicated in Fig. 3 together with some recent values $f_{i} u m$ the literature (7).

The authors are indebted to Dr. J. W. Meadows for valuable discussions. This work was supported by the U.S. Dept. of Energy.

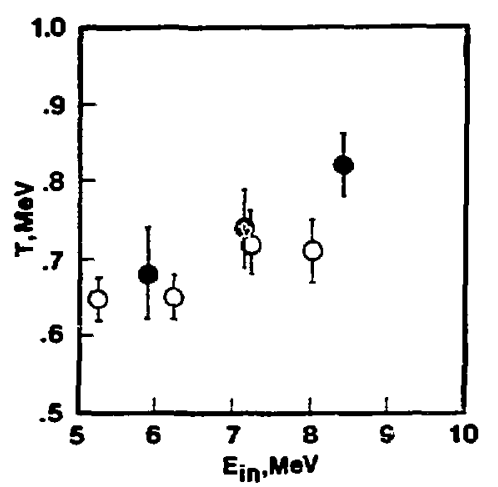

Fig. 3. Nb temperatures.' This work: $\bullet$, ref. $1: 0$.

\section{REFERENCES}

1. E. Cheng, Nuclear Data Needs for Fusion Energy Development, GA Technologies Inc., Report GA-A17881 (1985).

2. W. Poenitz and T. Tamura Nuclear Data for Sclence and Technology, ed. K. Böckhof $\bar{f}$ (D. Reidel Put. Holland, 1983) p. 465.

3. A. Smith, D. Smith and R. Howerton, ANL/NDM-88, Argonne National Laboratory (1985).

4. P. Guenther, Univ. of Illinols Thesis, Elastic and Inelastic Neutron Scattering from the Even Isotopes of Tungsten (1977).

5. A. Smlth, P. Guenther and R. Sjoblom, Nucl. Instr. and Methods, 140, 397 (1977).

6. J. Blatt and V. Weisskopf, Theoretical Nuclear Physics,

J. Wiley and Sons, New York, 1982 .

7. S. Simakov et al., Yadernaya FIz1ka, 374 (1983) 801. 


\section{DISCLAIMER}

This report was prepared as an account of work sponsored by an agency or the United States Government. Neither the United States Government nor any agency thereof, nor any of their employees, makes any warranty, express or implied, or assumes any legal liability or responsibility for the accuracy, completeness, or usefulness of any information, apparatus, product, or process disclosed, or represents that its use would not infringe privately owned rights. Reference herein to any specific commercial product, process, or service by trade name, trademark, manufacturer, or otherwise does not necessarily constitute or imply its endorsement, recommendation, or favoring by the United States Government or any agency thereof. The views and opinions of authors expressed herein do not necessarily state or reflect those of the United Statcs Government or any agency thereof. 